University of Wollongong

Research Online

Australian Institute for Innovative Materials -

Papers

Australian Institute for Innovative Materials

$1-1-2012$

\title{
Magnetostrictive properties of directional solidification Fe82Ga9Al9 alloy
}

Y Zhou

Tianjin University Of Commerce

X L. Wang

University of Wollongong, xiaolin@uow.edu.au

B W. Wang

Hebei University of Technology

Y Du

University of Wollongong, ydu@uow.edu.au

Y Liu

Tianjin University of Commerce

See next page for additional authors

Follow this and additional works at: https://ro.uow.edu.au/aiimpapers

Part of the Engineering Commons, and the Physical Sciences and Mathematics Commons

Research Online is the open access institutional repository for the University of Wollongong. For further information contact the UOW Library: research-pubs@uow.edu.au 


\title{
Magnetostrictive properties of directional solidification Fe82Ga9Al9 alloy
}

\begin{abstract}
"Fe82Ga9Al9 alloy rod was prepared by the directional solidification (DS) method. The effects of uniaxial compressive stress on magnetostriction of the alloy and the temperature dependence of magnetostriction were investigated. The results show that the magnetostriction increases from $135 \mathrm{x}$ $10(-6)$ at $2.3 \mathrm{MPa}$ to $221 \times 10(-6)$ at $53 \mathrm{MPa}$ and then remains at this value between $53 \mathrm{MPa}$ and $90 \mathrm{MPa}$. This enhancement results from domain rotation under the compressive stress. The temperature dependence results show that the saturated magnetostriction decreases by $11 \%$ ( 25 degrees $\mathrm{C}-120$ degrees $\mathrm{C}$ ) and $13 \%$ (25 degrees $\mathrm{C}-100$ degrees $\mathrm{C}$ ) for samples with $0 \mathrm{MPa}$ and $15 \mathrm{MPa}$ compressive stress applied, respectively. This decrease is due to reduced magnetic crystalline anisotropy as the temperature increases. Under the compressive stress conditions, the magnetostriction decreases more notably. (C) 2012 American Institute of Physics. [doi:10.1063/1.3679152]"
\end{abstract}

\section{Keywords}

magnetostrictive, alloy, properties, directional, solidification, fe82ga9al9

Disciplines

Engineering | Physical Sciences and Mathematics

\section{Publication Details}

Zhou, Y., Wang, X. L., Wang, B. W., Du, Y., Liu, Y. \& Liu, L. Q. (2012). Magnetostrictive properties of directional solidification Fe82Ga9A19 alloy. Journal of Applied Physics, 111 (7), 07A332-1-07A332-3.

\section{Authors}

Y Zhou, X L. Wang, B W. Wang, Y Du, Y Liu, and L Q. Liu 


\section{AIP Applied Physics}

Magnetostrictive properties of directional solidification Fe82Ga9A19 alloy

Y. Zhou, X. L. Wang, B. W. Wang, Y. Liu, Y. Du et al.

Citation: J. Appl. Phys. 111, 07A332 (2012); doi: 10.1063/1.3679152

View online: http://dx.doi.org/10.1063/1.3679152

View Table of Contents: http://jap.aip.org/resource/1/JAPIAU/v111/i7

Published by the American Institute of Physics.

\section{Related Articles}

Microstructures and magnetostrictive strains of Fe-Ga-Ni ferromagnetic shape memory alloys J. Appl. Phys. 113, 17A303 (2013)

Magnetoelectric effects in functionally graded multiferroic bilayers

J. Appl. Phys. 113, 084502 (2013)

A unified model for the dynamics of driven ribbon with strain and magnetic order parameters Chaos 23, 013116 (2013)

Giant self-biased magnetoelectric coupling in co-fired textured layered composites Appl. Phys. Lett. 102, 052907 (2013)

Magnetoimpedance dependence on width in Co66.5Fe3.5Si12.0B18.0 amorphous alloy ribbons J. Appl. Phys. 113, 053905 (2013)

\section{Additional information on J. Appl. Phys.}

Journal Homepage: http://jap.aip.org/

Journal Information: http://jap.aip.org/about/about_the_journal

Top downloads: http://jap.aip.org/features/most_downloaded

Information for Authors: http://jap.aip.org/authors

\section{ADVERTISEMENT}

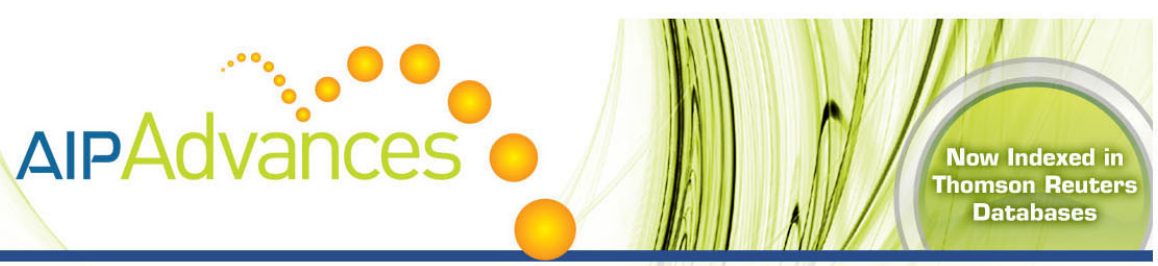

\section{Explore AIP's open access journal: • Rapid publication \\ - Article-level metrics \\ - Post-publication rating and commenting}




\title{
Magnetostrictive properties of directional solidification $\mathrm{Fe}_{82} \mathrm{Ga}_{9} \mathrm{Al}_{9}$ alloy
}

\author{
Y. Zhou, ${ }^{1,2, a)}$ X. L. Wang, ${ }^{2}$ B. W. Wang, ${ }^{3}$ Y. Liu, ${ }^{1}$ Y. Du, ${ }^{2}$ Y. C. Niu, ${ }^{4}$ and L. Q. Liu ${ }^{4}$ \\ ${ }^{1}$ School of Science, Tianjin University of Commerce, Tianjin 300134, China \\ ${ }^{2}$ Institute for Superconducting and Electronic Materials, University of Wollongong, Wollongong, NSW 2522, \\ Australia \\ ${ }^{3}$ Research Center for Magnetic Techniques and Magnetic Materials, Hebei University of Technology, Tianjin \\ 300130, China \\ ${ }^{4}$ School of Material Science Engineering, Shandong Jianzhu University, Jinan 250101, Shandong, China
}

(Presented 3 November 2011; received 21 September 2011; accepted 5 December 2011; published online 17 February 2012)

\begin{abstract}
$\mathrm{Fe}_{82} \mathrm{Ga}_{9} \mathrm{Al}_{9}$ alloy rod was prepared by the directional solidification (DS) method. The effects of uniaxial compressive stress on magnetostriction of the alloy and the temperature dependence of magnetostriction were investigated. The results show that the magnetostriction increases from $135 \times 10^{-6}$ at $2.3 \mathrm{MPa}$ to $221 \times 10^{-6}$ at $53 \mathrm{MPa}$ and then remains at this value between $53 \mathrm{MPa}$ and $90 \mathrm{MPa}$. This enhancement results from domain rotation under the compressive stress. The temperature dependence results show that the saturated magnetostriction decreases by $11 \%$ $\left(25^{\circ} \mathrm{C}-120^{\circ} \mathrm{C}\right)$ and $13 \%\left(25^{\circ} \mathrm{C}-100^{\circ} \mathrm{C}\right)$ for samples with $0 \mathrm{MPa}$ and $15 \mathrm{MPa}$ compressive stress applied, respectively. This decrease is due to reduced magnetic crystalline anisotropy as the temperature increases. Under the compressive stress conditions, the magnetostriction decreases more notably. (C) 2012 American Institute of Physics. [doi:10.1063/1.3679152]
\end{abstract}

\section{INTRODUCTION}

Both of the non-magnetic elements $\mathrm{Ga}$ and $\mathrm{Al}$ can enhance the magnetostriction $\lambda$ of body-centered cubic (bcc) $\mathrm{Fe}$ in the [100] direction. The two elements have a filled $d$-shell and no $d$-shell, respectively. The outer shell configurations of $\mathrm{Ga}\left(4 \mathrm{~s}^{2} 4 \mathrm{p}^{1}\right)$ and $\mathrm{Al}\left(3 \mathrm{~s}^{2} 3 \mathrm{p}^{1}\right)$ are also similar. Galfenol (Fe-Ga) alloys are known to have appreciable low field magnetostriction, good mechanical properties, and relatively low cost. ${ }^{1-4}$ Clark et al. ${ }^{3,5}$ have found that the magnetostriction of Fe-Ga alloys exhibits a complicated dependence on Ga concentration. Two magnetostriction peaks occur near $\mathrm{Fe}_{82} \mathrm{Ga}_{18}$ and $\mathrm{Fe}_{72} \mathrm{Ga}_{28}$, respectively. It is commonly believed that the first magnetostrictive peak is the result of preferential (100) Ga-Ga pairing in the disordered bcc structure, ${ }^{6}$ and the second peak appears because the drop in the elastic constant $C^{\prime}$ enhances the magnetostriction. ${ }^{7}$

$\mathrm{Fe}-\mathrm{Al}$ alloys have some advantages over Fe-Ga alloys in large-scale applications and have greater durability. As combinations of both alloys, $\mathrm{Fe}-\mathrm{Ga}-\mathrm{Al}$ alloys ${ }^{3}$ have shown a roughly linear decrease in magnetostriction with increasing $\mathrm{Al}$ content. However, the replacement of a small fraction of Fe atoms by $\mathrm{Al}$ enhances the magnetostriction of the Fe-based alloys. ${ }^{8}$ Furthermore, the magnetostriction of $\mathrm{Fe}_{87} \mathrm{Ga}_{4} \mathrm{Al}_{9}\langle 100\rangle$ single crystals was found to increase from $250 \times 10^{-6}$ at applied compressive stress of $10.3 \mathrm{MPa}$ to $290 \times 10^{-6}$ at $96.5 \mathrm{MPa} .^{3}$

In this work we report the effects of compressive stress on the magnetostrictive properties of directional solidification (DS) $\mathrm{Fe}_{82} \mathrm{Ga}_{9} \mathrm{Al}_{9}$ alloy and the temperature dependence of the magnetostriction. It is shown that $\mathrm{Fe}-\mathrm{Ga}-\mathrm{Al}$ alloys have large low field magnetostriction, and that uniaxial compressive stress can significantly enhance the magnetostric-

\footnotetext{
a) Author to whom correspondence should be addressed. Electronic mail: 1xyzhy@tjcu.edu.cn.
}

tion, while the magnetostriction decreases slightly with increasing temperature.

\section{EXPERIMENTAL METHODS}

Appropriate quantities of pure $\mathrm{Fe}$ (99.9wt. \%), Ga (99.99wt. \%), and Al (99.99wt. \%) were well mixed and arc-melted together 3 or three or four times under an argon atmosphere. The weight of each sample was $10 \mathrm{~g}$ and the weight loss of each sample was controlled to below $1 \mathrm{wt}$. \%. The resulting ingots, separately wrapped in molybdenum foil, were sealed in quartz capsules and heat-treated at $1100{ }^{\circ} \mathrm{C}$ for $3 \mathrm{~h}, 1000^{\circ} \mathrm{C}$ for $120 \mathrm{~h}$, and then $730^{\circ} \mathrm{C}$ for $168 \mathrm{~h}$ to achieve homogeneity. Some alloys were also prepared using a directional solidification (DS) furnace that was specially designed for the one-step process. ${ }^{9}$ After the directional solidification was finished, the sample rod in the quartz tube was homogenized at $1150^{\circ} \mathrm{C}$ for $1 \mathrm{~h}$ and $850^{\circ} \mathrm{C}$ for $3 \mathrm{~h}$ before wind cooling. The DS rod for measurements has a diameter of $10 \mathrm{~mm}$ and length of $25 \mathrm{~mm}$.

$\mathrm{X}$-ray diffraction (XRD) analysis was carried out in a Philips X'Pert MPD diffractometer with $\mathrm{Cu}-\mathrm{K}_{\alpha}$ radiation. The lattice parameters and the crystal structure were refined using the Rietica software package (VISION 1.7.7). The magnetostriction was measured by standard strain gauge techniques ${ }^{10}$ using a NIM-2000 magnetic measurement system and SDY2202 static digital strain gauge apparatus with sensitive area of $3 \mathrm{~mm} \times 2 \mathrm{~mm}$.

\section{RESULTS AND DISCUSSION}

The XRD results for the $\mathrm{Fe}_{82} \mathrm{Ga}_{18-x} \mathrm{Al}_{x}(x=1.5,3,3.6$, $4.5,6,7.5,9,10.5,12,13.5$, and 15) alloys indicate that all the alloys in this series have the same crystal structure. As an example, Fig. 1 shows the XRD pattern and refinement results for $\mathrm{Fe}_{82} \mathrm{Ga}_{9} \mathrm{Al}_{9}$ alloy, homogenized at $1100{ }^{\circ} \mathrm{C}$ for 


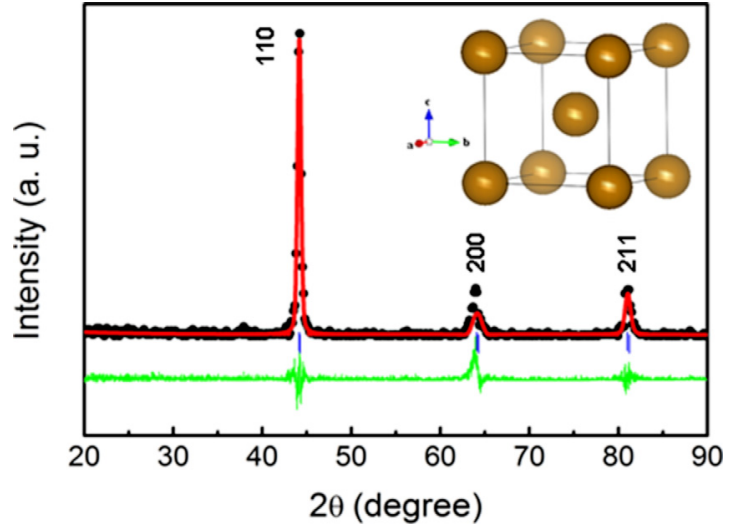

FIG. 1. (Color online) Measured (dots) and calculated (line) XRD patterns of $\mathrm{Fe}_{82} \mathrm{Ga}_{9} \mathrm{Al}_{9}$ alloy, with the bottom spectrum marking the standardline positions. Inset shows the unit cell.

$3 \mathrm{~h}, 1000^{\circ} \mathrm{C}$ for $120 \mathrm{~h}$, and then $730^{\circ} \mathrm{C}$ for $168 \mathrm{~h}$. The results indicate that the sample is single phase, crystallizing in the disordered $\alpha$-Fe structure (A2) with space group $\operatorname{Im} \overline{3} m$ and lattice parameter $a=2.848(8) \AA$.

The effects of $\mathrm{Al}$ concentration on the saturated magnetostriction of $\mathrm{Fe}_{82} \mathrm{Ga}_{18-x} \mathrm{Al}_{x}$ alloys are shown in Fig. 2. It can be found that the saturated magnetostriction of the alloys increases with increasing $\mathrm{Al}$ concentration in the range of $x<9$, and then it decreases for $9 \leq x \leq 15$. Clearly, the $\mathrm{Fe}_{82} \mathrm{Ga}_{9} \mathrm{Al}_{9}$ alloy has the maximum magnetostriction, up to $88 \times 10^{-6}$, which is higher than that of polycrystalline $\mathrm{Fe}_{80} \mathrm{Ga}_{20}$ alloy. ${ }^{11}$ However, high substitution amounts of $\mathrm{Al}$ tend to decrease magnetostriction of the Fe-Ga-Al alloys.

It was reported that the magnetostriction of $\mathrm{Fe}_{100-x} \mathrm{Al}_{x}$ or $\mathrm{Fe}_{100-x} \mathrm{Ga}_{x}$ alloys increases with increasing $x$ for $x<19$ due to $\mathrm{Ga}-\mathrm{Ga}$ and $\mathrm{Al}-\mathrm{Al}$ pairings. ${ }^{6}$ Wutting et al. ${ }^{7}$ have proposed a magnetostriction model based on Ga pairs along the $\langle 100\rangle$ direction. $\langle 100\rangle$ next-nearest Ga substitutional pairs in bcc alloys cause short range order, and these pairs create a local tetragonal stress that results in a cubic-to-tetragonal transformation. Therefore, the magnetostriction of the Fe-Ga alloys is proportional to the concentration of Ga pairs.

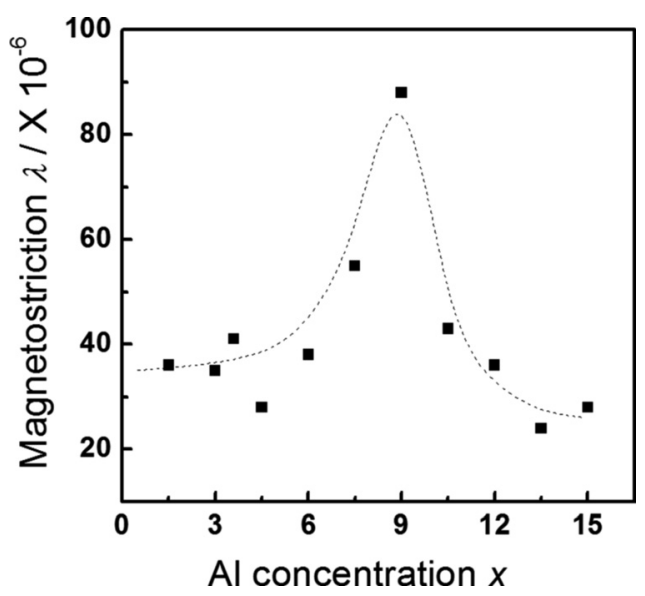

FIG. 2. Al concentration $x$ dependence of the magnetostriction of $\mathrm{Fe}_{82} \mathrm{Ga}_{18-x} \mathrm{Al}_{x}(x=1.5,3,3.6,4.5,6,7.5,9,10.5,12,13.5$, and 15) alloys at a saturation magnetic field. The samples were prepared using the arc melting method, and magnetostrictive measurements were carried out at room temperature for $0 \mathrm{MPa}$ stress.
Our results also provide experimental support to this model of $\mathrm{Ga}$ or $\mathrm{Al}$ pairs. According to the phase diagram, ${ }^{12}$ $\mathrm{Fe}_{82} \mathrm{Ga}_{9} \mathrm{Al}_{9}$ alloy has disordered A2 structure after heat treatment. However, it seems that this alloy composition is beneficial to the formation of more $\mathrm{Ga}$ or $\mathrm{Al}$ pairs. The $\mathrm{Ga}-\mathrm{Ga}$ or $\mathrm{Al}-\mathrm{Al}$ pairings along $\langle 100\rangle$ induce changes in the internal stress, resulting in the enhancement of the magnetostriction of $\mathrm{Fe}_{82} \mathrm{Ga}_{9} \mathrm{Al}_{9}$.

The XRD patterns of the alloys prepared by the DS method suggest a $\langle 100\rangle$ preferred orientation along the rod axis. It is well known that magnetostrictive devices usually are used under stress conditions because an applied mechanical stress can alter the domain structure of the magnetostrictive material and create a new source of magnetic anisotropy. The effect of stress on the magnetomechanical response of the $\mathrm{DS} \mathrm{Fe}_{82} \mathrm{Ga}_{9} \mathrm{Al}_{9}$ rod is shown in Fig. 3. It can be seen that the maximum magnetostriction increases with increasing compressive stress from $135 \times 10^{-6}$ for $0 \mathrm{MPa}$ to $221 \times 10^{-6}$ for $53 \mathrm{MPa}$.

When a uniaxial compressive stress is applied along the axis of the rod, in response to the magnetoelastic energy the saturation magnetization, $M_{S}$, vectors of the domains rotate to perpendicular to the axis. Here, magnetic field parallel to the axis of the rod was applied, and the stress axis becomes a hard axis, because the field now has to supply energy that is equal to the magnetoelastic energy for rotating the $M_{S}$ vectors of the domains into the field direction. When the rotation is complete, the magnetostriction reaches saturation. Thus, the magnetostriction increases with increasing applied uniaxial compressive stress, as is shown in inset of Fig. 3. It also can be found that the magnetostriction hardly changes from $53 \mathrm{MPa}$ to $90 \mathrm{MPa}$ due to the saturated state.

From Fig. 3, we can see that for loading conditions over $10 \mathrm{MPa}$, the magnetostriction begins to decrease as the applied magnetic field exceeds the saturated field. The existence of the magnetostrictive peaks may be related to internal texture, which is similar to a phenomenon reported in [110] texture iron single crystals. ${ }^{10}$ Initially, the magnetostriction arises from the wall motion of [100] and [010] domains.

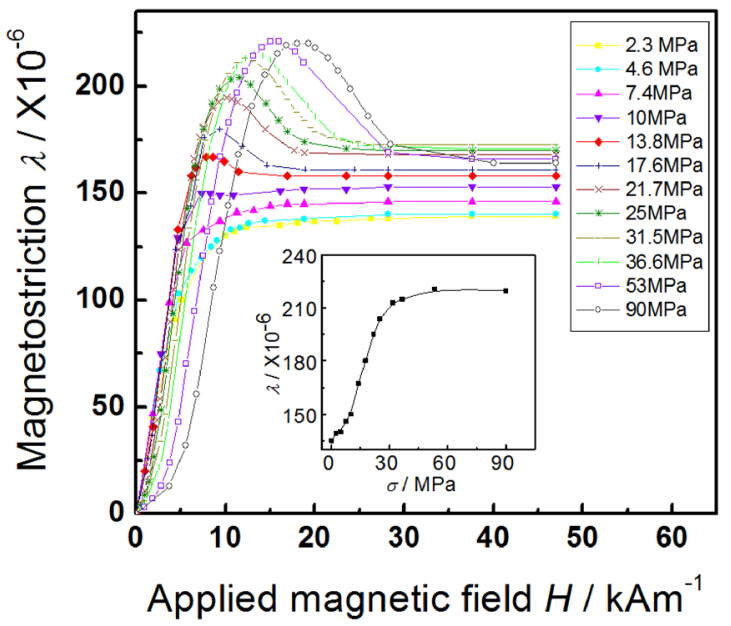

FIG. 3. (Color online) Applied magnetic field dependence of magnetostriction for the $\mathrm{DS} \mathrm{Fe}_{82} \mathrm{Ga}_{9} \mathrm{Al}_{9}$ rod, which was heat-treated at $1150^{\circ} \mathrm{C}$ for $1 \mathrm{~h}$ and $850^{\circ} \mathrm{C}$ for $3 \mathrm{~h}$ at $2.3-90 \mathrm{MPa}$. Inset shows that the compressive stress dependence of saturated magnetostriction of the sample. 
When an applied field $H$ is along the [110] direction, in response to the applied field, $90^{\circ}$ and $180^{\circ}$ wall motion will take place, which causes the disappearance of [001] and $[00 \overline{1}]$ domains and expansion in the [110] direction. With further increase in field, the rotation of [100] and [010] domains causes an additional strain of $\lambda_{111}$ along [110]. Because $\lambda_{111}$ is negative, the strain is a contraction at high field. Therefore, peaks in the magnetostriction can be observed.

The improvement in the magnetostriction performance indicates that $\mathrm{DS} \mathrm{Fe}_{82} \mathrm{Ga}_{9} \mathrm{Al}_{9}$ alloy is a potential candidate for magnetostrictive actuator and transducer applications. To investigate the temperature dependence of the magnetostriction of the $\mathrm{DS} \mathrm{Fe}_{82} \mathrm{Ga}_{9} \mathrm{Al}_{9}$ alloy rod, the magnetostriction versus applied magnetic field relationship was measured under $0 \mathrm{MPa}$ and $15 \mathrm{MPa}$ compressive stress conditions. Figure 4 shows magnetostriction curves at $0 \mathrm{MPa}$ for various temperatures. The results indicate that the alloy has a highly linear magnetostriction curve and low hysteresis, while the saturated field hardly changes. However, the magnetostriction experiences only a little constriction with increasing temperature for applied fields above $10 \mathrm{kA} / \mathrm{m}$. The performance is similar to that of $\mathrm{Fe}_{0.81} \mathrm{Ga}_{0.19}$ at $45.3 \mathrm{MPa}$ for various temperatures. ${ }^{13}$ This indicates that no abnormal changes in the $\lambda_{100}$ or $\lambda_{111}$ magnetostriction are occurring. Figure 5 shows the maximum magnetostriction values at various temperatures and $18.8 \mathrm{kA} / \mathrm{m}$ applied field for $0 \mathrm{MPa}$ and $15 \mathrm{MPa}$ stress. When the compressive stress is $0 \mathrm{MPa}$, the maximum magnetostriction declines only $11 \%$ from $25^{\circ} \mathrm{C}$ to $120^{\circ} \mathrm{C}$, and the temperature dependence $(\Delta \lambda / \Delta \mathrm{T})$ is only $-0.16 \times 10^{-6} /{ }^{\circ} \mathrm{C}$. The relatively slight decrease suggests that the anisotropy constants $K_{1}$ or $K_{2}$ are subject to no abnormal changes with increasing temperature. However, the magnetostriction declines more significantly, but still slowly up to $13 \%$, from $25^{\circ} \mathrm{C}$ to $100^{\circ} \mathrm{C}$, and the temperature dependence is $-0.31 \times 10^{-6} /{ }^{\circ} \mathrm{C}$ when the stress is $15 \mathrm{MPa}$. These temperature dependencies of maximum magnetostriction are similar to the trends for $\mathrm{Fe}_{83} \mathrm{Ga}_{17}{ }^{8}$ It is also observed that there is a discontinuous decline in the magnetostriction around $70^{\circ} \mathrm{C}$ at $15 \mathrm{MPa}$. A similar change at about $70^{\circ} \mathrm{C}$ has also been observed in the temperature dependence of the maximum magnetostriction of $\mathrm{Fe}_{0.81} \mathrm{Ga}_{0.19}$ for a $45.3 \mathrm{MPa}$ compressive stress. ${ }^{13}$ At the moment, the

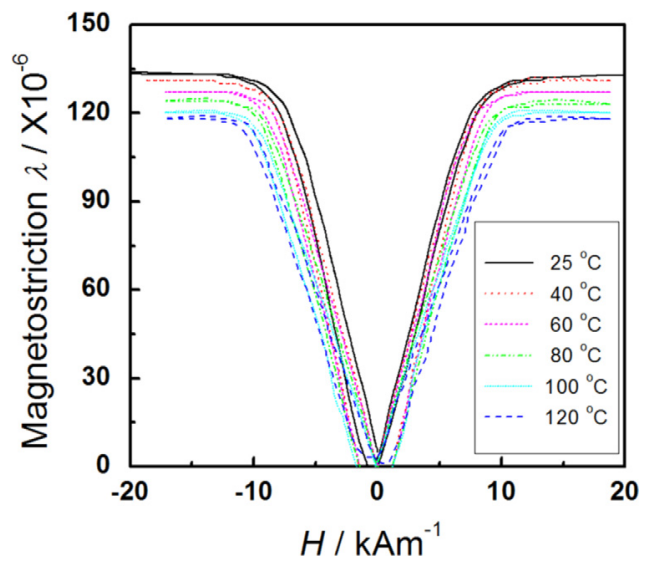

FIG. 4. (Color online) Applied magnetic field dependence of magnetostriction of the $\mathrm{DS} \mathrm{Fe}_{82} \mathrm{Ga}_{9} \mathrm{Al}_{9}$ rod at various temperatures for $0 \mathrm{MPa}$ applied stress.

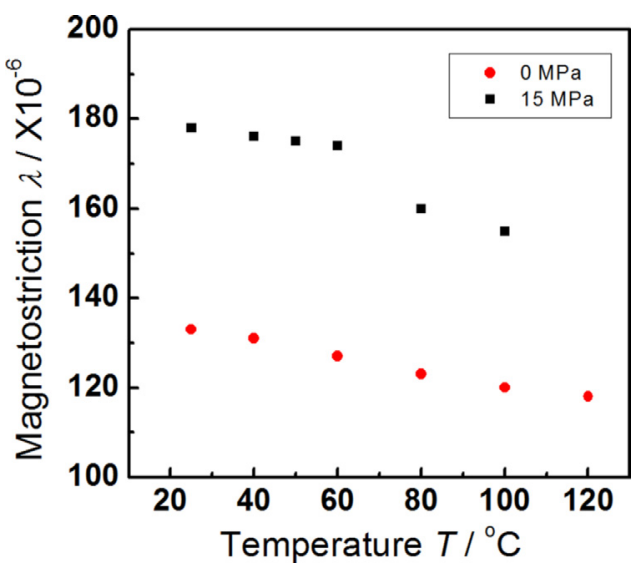

FIG. 5. (Color online) Temperature dependence of magnetostriction of the DS $\mathrm{Fe}_{82} \mathrm{Ga}_{9} \mathrm{Al}_{9}$ rod at $25-120^{\circ} \mathrm{C}$ for $0 \mathrm{MPa}$ and $25-100^{\circ} \mathrm{C}$ for $15 \mathrm{MPa}$ stress.

underlying physics is not understood. However, it might be a result of compressive stress inducing a structural transition in the alloy at some high temperature.

\section{CONCLUSIONS}

In summary, we have studied the effects of uniaxial compressive stress on the magnetostriction of $\mathrm{Fe}_{82} \mathrm{Ga}_{9} \mathrm{Al}_{9}$ alloy and the temperature dependence of the magnetostriction. The results indicate that $\mathrm{DS} \mathrm{Fe}_{82} \mathrm{Ga}_{9} \mathrm{Al}_{9}$ alloy has stable magnetostriction of about $221 \times 10^{-6}$ under high compressive stress (53 MPa-90 MPa). The $\mathrm{Fe}_{82} \mathrm{Ga}_{9} \mathrm{Al}_{9}$ alloy also shows weak temperature dependence $\left(\geq-0.31 \times 10^{-6} /{ }^{\circ} \mathrm{C}\right)$ over a wide temperature range $\left(25-120^{\circ} \mathrm{C}\right)$. The stability under compressive stress and the weak temperature dependence indicate that this alloy might be a potential candidate for industrial or military applications in smart actuators and transducers.

\section{ACKNOWLEDGMENTS}

This project is supported by the National Natural Science Foundation of China (50971056, 51171057), Tianjin Municipal Education Commission of China (20100314) and the Australian Research Council through two Discovery projects (DP0987190 and DP1094073).

${ }^{1}$ C. Mudivarthi, M. Laver, J. Cullen, A. Flatau, and M. Wutting, J. Appl. Phys. 107, 09A957 (2010).

${ }^{2}$ T. Saito and K. Sudo, J. Appl. Phys. 109, 07A925 (2011).

${ }^{3}$ A. Clark, M. Wun-Fogle, J. Restorif, K. Dennis, T. Lograsso, and R. McCallum, J. Appl. Phys. 95, 6942 (2004).

${ }^{4}$ M. P. Ruffoni, S. Pascarelli, R. Grossioner, R. S. Turtelli, C. Bormionunes, and R. F. Pettifer, Phys. Rev. Lett. 101, 147202 (2008).

${ }^{5}$ R. Kellogg, A. Flatau, A. Clark, M. Wun-Fogle, and T. Lograsso, J. Appl. Phys. 93, 8495 (2003)

${ }^{6}$ J. Cullen, A. Clark, M. Wun-Fogle, J. Restorif, and T. Lograsso, J. Magn. Magn. Mater. 948, 226 (2001)

${ }^{7}$ M. Wuttig, L. Dai, and J. Cullen, Appl. Phys. Lett. 80, 1135 (2002).

${ }^{8}$ A. Clark, J. Restorif, M. Wun-Fogle, T. Lograsso, and D. Schlagel, IEEE Trans. Magn. 36, 3238 (2000).

${ }^{9}$ S. Zhang, K. Li, D. Yu, et al., J. Rare Earths 26, 388 (2008).

${ }^{10} \mathrm{~B}$. D. Cullity and C. Graham, Introduction to Magnetic Materials (Wesley-IEEE Press, Hoboken, NJ, 2009).

${ }^{11}$ S. Guruswamy, N. Srisukhumbowornchai, A. E. Clark, J. B. Restorf, and M. Wun-Fogle, Scr. Mater. 43, 239 (2000).

${ }^{12}$ Y. Zhou, B. W. Wang, S. Y. Li, W. M. Huang, and S. Y. Cao, Int. J. Mater. Res. 99, 251 (2008).

${ }^{13}$ R. A. Kellogg, A. B. Flatau, A. E. Clark, M. Wun-Fogle, and T. A. Lograsso, J. Appl. Phys. 91, 7821 (2002). 